\title{
Electron loss and meteoric dust in the mesosphere
}

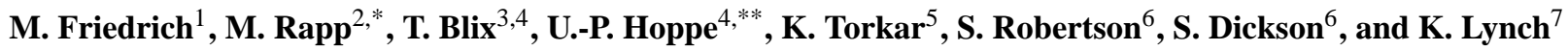 \\ ${ }^{1}$ Graz University of Technology, Graz, Austria \\ ${ }^{2}$ Leibniz Institute of Atmospheric Physics, Kühlungsborn, Germany \\ ${ }^{3}$ Norwegian Defence Research Establishment, Kjeller, Norway \\ ${ }^{4}$ University of Oslo, Norway \\ ${ }^{5}$ Space Research Institute, Austrian Academy of Sciences, Graz, Austria \\ ${ }^{6}$ Department of Physics, University of Colorado, Boulder, USA \\ ${ }^{7}$ Department of Physics and Astronomy, Hanover, NH 03755, USA \\ *now at: German Aerospace Center, Institute of Atmospheric Physics, Oberpfaffenhofen, Germany \\ ** on leave from: Norwegian Defence Research Establishment, Kjeller, Norway
}

Correspondence to: M. Friedrich (martin.friedrich@tugraz.at)

Received: 6 August 2012 - Accepted: 19 September 2012 - Published: 5 October 2012

\begin{abstract}
The ionosphere is always assumed to contain equal numbers of positive and negative charges in a given volume (quasineutrality). Hence fewer electrons than positive charges are an indication of negative charges other than electrons. Theories predict and in-situ mass spectrometer measurements confirmed that these negative charges are negative ions, but recent experimental results suggest that other scavengers of free electrons can also be active in the mesosphere. Outside the polar summer mesosphere this additional removal of electrons is today believed to be due to meteoric dust, which maximises in the mesosphere. Data predominantly from the recent ECOMA flights are used to test this presumption. Six sounding rockets carried different dust detectors, as well as probes for electrons and ions. With such an instrumental ensemble one can assess whether indeed the existence of meteoric dust removes more electrons than would be expected from gas phase ion chemistry alone. Other factors potentially impacting on electron removal are also discussed in the paper.
\end{abstract}

Keywords. Atmospheric composition and structure (Aerosols and particles)

\section{Introduction}

The ionosphere's plasma is the result of a balance between ionisation from various sources and reverse reactions again leading to neutrals. At high latitudes, notably at night, the most important source of ionisation is provided by energetic electrons precipitating out of the magnetosphere. The ionosphere is quasi-neutral, i.e. the number densities of positive and negative particles is equal. Hence the number density of negative charges $N^{-}$- other than electrons - can be obtained by forming the difference between positive charges and electrons. The primary products of ionisation are free electrons $\left(N_{\mathrm{e}}\right)$ and (primary) positive ions; both these species can not only simply recombine in the reverse reaction (dissociative recombination), but may experience several intermediate stages before eventually again leading to neutrals. Figure 1 shows a very basic chemical scheme of the most important ion reactions active in the mesosphere. We will here concentrate on the negative plasma species such as free electrons, negative ions, but also negatively charged larger particles presumably consisting of aerosol particles or meteoric dust. In the above scheme, negative ions $X^{-}$are formed by a three-body attachment (coefficient $\beta$ ) of electrons involving the background (number density $M$ ) onto $X$. The reverse reactions in this simple chemical scenario are via atomic oxygen $\mathrm{O}$ and by photo detachment. As far as negative ions are concerned, the chemical scheme in Fig. 1 is sufficient to qualitatively understand the observations reported in this paper. For the case of negatively charged particles $\left(P^{-}\right)$, their formation is through direct electron attachment on neutral particles $(P)$ while their sink is either recombination with positive ions or photo detachment (cf. e.g. Rapp, 2009). Importantly,

Published by Copernicus Publications on behalf of the European Geosciences Union. 



negative species

Fig. 1. Simplified ion-chemistry in the mesosphere (D-region). Ions in the shaded boxes are the ones primarily produced. For graphical reasons the reactions between the negative species $\left(e^{-}, X^{-}\right.$, and $\left.P^{-}\right)$to all of the positive species are omitted $(M=$ background number density, $\mathrm{NO}=$ nitric oxide, $\mathrm{O}=$ atomic oxygen, $\mathrm{P}=$ particle).

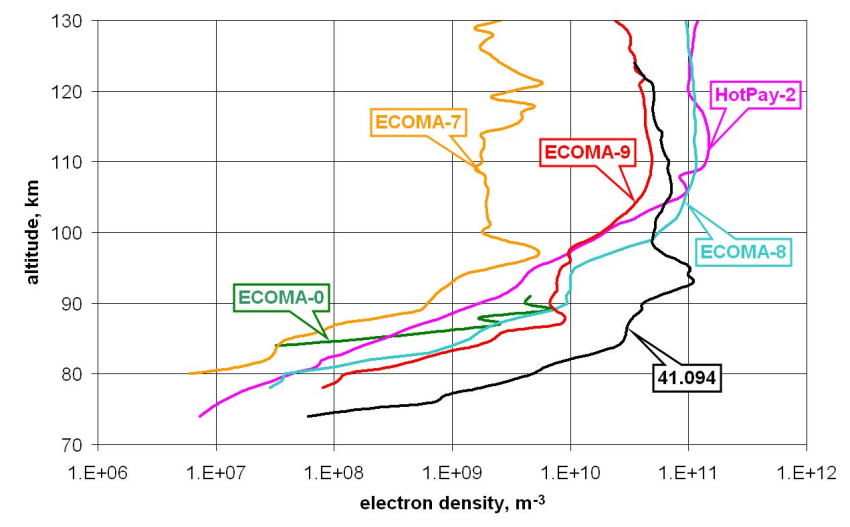

Fig. 2. Night time electron density profiles of rocket flights which carried particle detectors and positive ion probes. The profile ECOMA-7 is the lowest ever measured at auroral latitudes.

atomic oxygen is not thought to play any role in the charging of these large particles.

Under normal circumstances atomic oxygen at night only occurs above a pronounced ledge usually located between 83 and $88 \mathrm{~km}$ (Gumbel, 1997). If the ledge of the O-onset is not very sudden, but shows structures, they are - as one would expect - indeed reflected in similar structures in the electron densities (Friedrich et al., 1999). Since photo detachment at night is largely absent - or at best provided by scattered sunlight - the loss of negative ions is primarily by ion-ion recombination (with coefficient $\alpha_{\mathrm{i}}$ ) and the following relation between the number densities of electrons $N_{\mathrm{e}}$, and positive charges $N^{+}$applies (cf. e.g. Friedrich et al., 2011):
$N_{\mathrm{e}}=\frac{N^{+}}{1+\frac{\beta}{\alpha_{\mathrm{i}}} \frac{M^{2}}{N^{+}}}$

In other words, in absence of larger negatively charged particles, $N^{+}$and $N_{\mathrm{e}}$ should be predictably related provided $\beta / \alpha_{\mathrm{i}}$ is known and independent of altitude. A study of 28 rocket flights where both electrons and positive ions were measured revealed that $\beta / \alpha_{\mathrm{i}}$ scatters widely about the values expected from laboratory measurements, which was tentatively ascribed to additional electron loss by attachment to targets larger than molecules, such as irregularly occurring meteoric dust (Friedrich et al., 2011). At this time there are six rocket flights instrumented to measure charged dust, electrons and ions which can substantiate this hypothesis. The ECOMA flights 7, 8 and 9 had practically identical trajectories, almost identical mechanical design and therefore comparable aerodynamical behaviour (see Rapp et al., 2011, for a general introduction to the ECOMA project). In addition, three other rockets with similar scientific instrumentation were launched between 2004 and 2011.

\section{Data and instrumentation}

Free electrons are continuously produced by ionisation due to sources predominantly originating from the Sun. At night only galactic cosmic rays and scattered solar UV remains (i.e. from the geocorona), but at high geomagnetic latitudes precipitating energetic charged particles provide an ionisation source largely independent of the time of the day. In Fig. 2 six electron density profile are depicted which were 

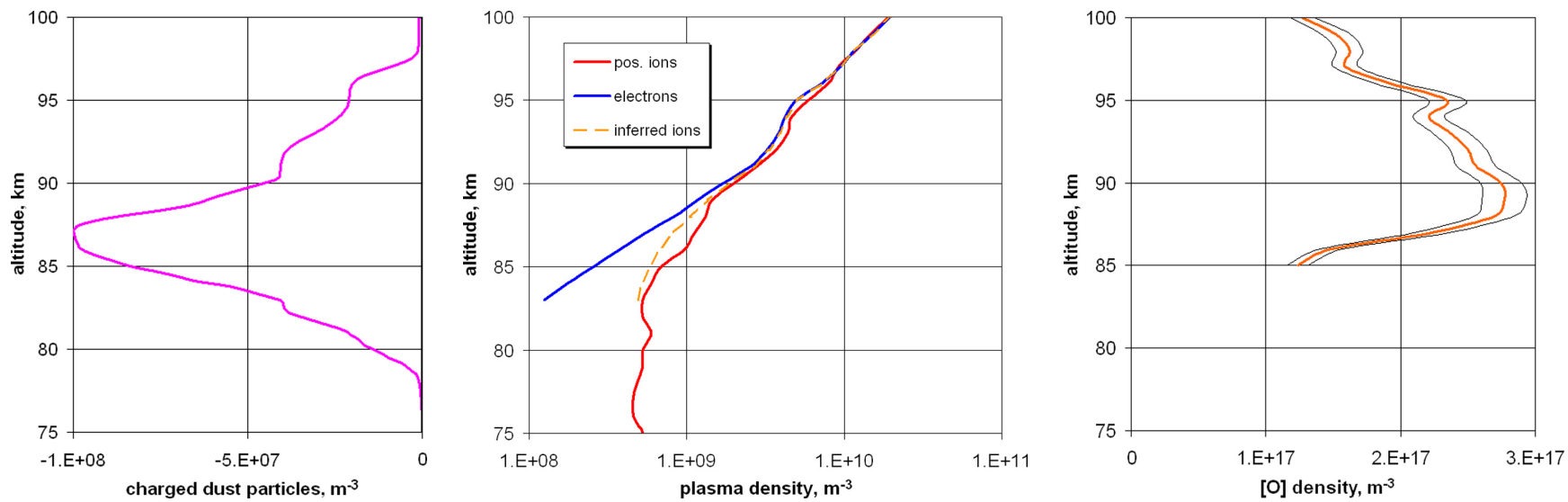

Fig. 3. Negative charged particles (left panel), plasma densities (electrons, ions and inferred ions, centre) and atomic oxygen (right panel) with error limits in the retrieval (flight HotPay-2).

Table 1. List of flights with particle detectors together with electron and ion density measurements.

\begin{tabular}{|c|c|c|c|c|c|c|c|c|c|}
\hline Code & Date & $\begin{array}{l}\text { Time } \\
\text { UT }\end{array}$ & $\begin{array}{c}x \\
\operatorname{deg}\end{array}$ & F10.7 & $a_{p}$ & $\begin{array}{c}\text { Riometer } \\
\mathrm{dB} @ 27.6 \\
\mathrm{MHz}\end{array}$ & Range & $\begin{array}{l}\beta / \alpha_{\mathrm{i}} \\
\mathrm{m}^{3}\end{array}$ & Comments \\
\hline ECOMA-0 & $2004-10-28$ & 19:49 & 120.1 & 118.5 & 3 & 0.003 & Esrange & $4.5 \times 10^{-31}$ & $\begin{array}{l}\text { low apogee; large angle of } \\
\text { attack }\end{array}$ \\
\hline HotPay-2 & $2008-01-31$ & 19:14 & 116.6 & 62.9 & 23 & 0.006 & Andøya & $5.0 \times 10^{-32}$ & $\begin{array}{l}\text { high apogee } \rightarrow \text { poor height } \\
\text { resolution in the meso- } \\
\text { sphere }\end{array}$ \\
\hline ECOMA-7 & 2010-12-04 & 04:21 & 112.9 & 76.4 & 0 & 0.000 & Andøya & $3.0 \times 10^{-32}$ & all-time low $\mathrm{Ne}$ \\
\hline ЕСОМА-8 & $2010-12-13$ & 03:24 & 119.1 & 76.5 & 23 & 0.104 & Andøya & $1.0 \times 10^{-31}$ & Geminid shower \\
\hline ECOMA-9 & $2010-12-19$ & $02: 36$ & 123.6 & 70.4 & 5 & 0.006 & Andøya & $8.0 \times 10^{-32}$ & \\
\hline 41.094 & 2011-10-11 & $21: 15$ & 116.2 & 130.1 & 2 & 0.420 & Andøya & $1.4 \times 10^{-31}$ & $\begin{array}{l}\text { small angle of attack; mass } \\
\text { spectrometer }\end{array}$ \\
\hline
\end{tabular}

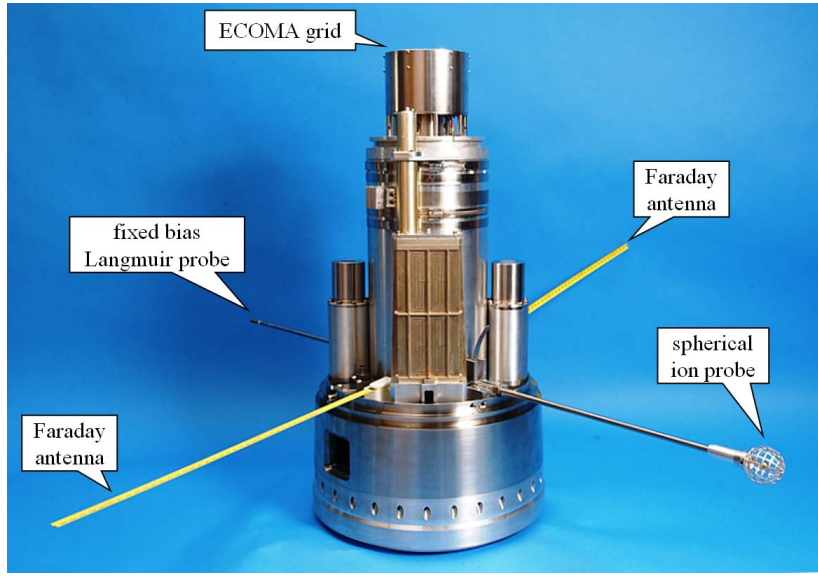

Fig. 4. Forward section of an ECOMA payload in flight configuration. measured by rocket payloads that also carried ion density probes and detectors for heavy particles. Among them the profile due to ECOMA-7 is not only the smallest in this collection, but also the smallest electron profile ever measured by a radio wave propagation experiment at auroral latitudes. A prototype of the ECOMA series of nine flights was flown from Esrange, Sweden, in October 2004. It carried the first of the ECOMA particle detectors (see below). The flight was a free ride on an otherwise experimental rocket launch. As a consequence of this uncoordinated flight opportunity, the apogee was only $95 \mathrm{~km}$ which meant that the particles' velocity into the detector when passing the mesosphere was somewhat low; additionally, the angle of attack (rocket axis vs. velocity vector) was relatively large and the slanting impact of the particles inside the detector may have distorted the measurements (Kassa et al., 2012; Rapp et al., 2005). This flight, termed ECOMA-0 in Table 1, is only listed for completeness.

In January 2008 the rocket payload HotPay-2 was launched from the Andøya Rocket Range, Norway, and 

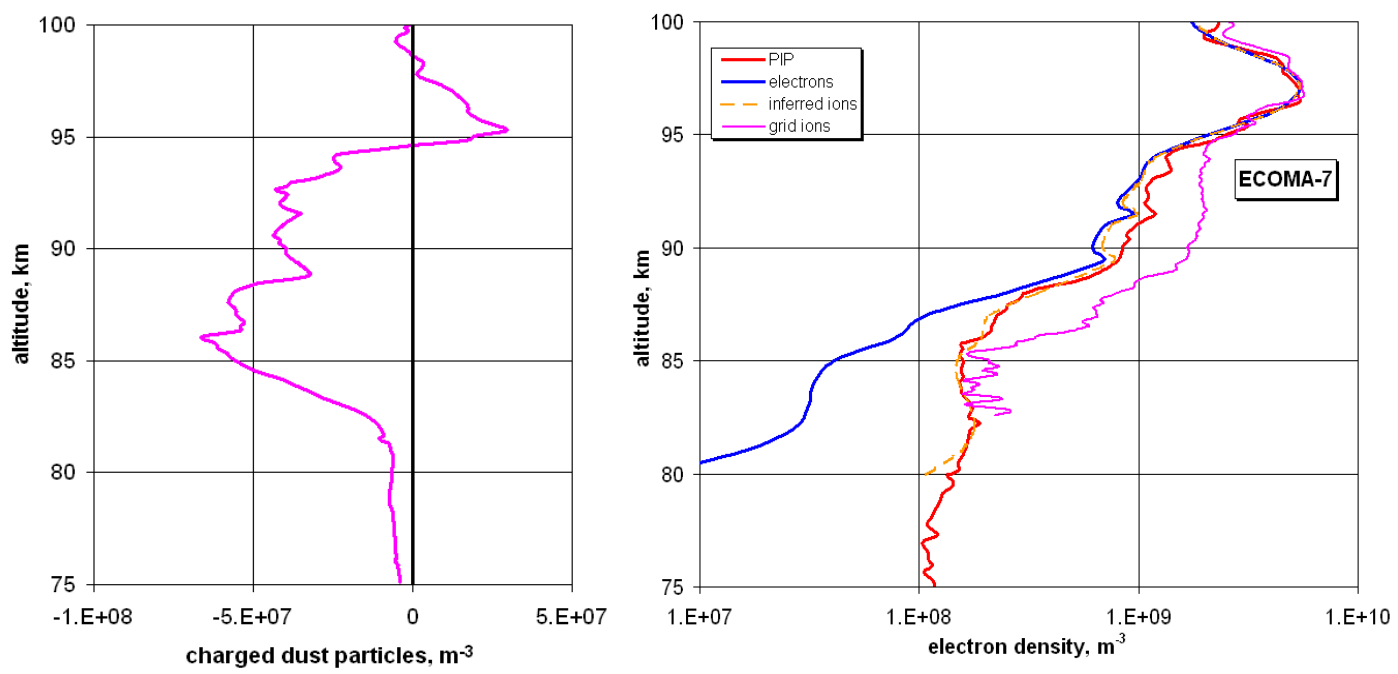

Fig. 5. Naturally charged dust collected by the ECOMA instrument in flight 7 (left panel). The negative sign indicates that the particles were negatively charged, the positive current seen in the ECOMA dust data above $95 \mathrm{~km}$ is not an indication of positively charged dust, but rather a sign of incomplete shielding against positive ions (Rapp et al., 2011). Electron and ion densities measured in the same flight (right panel); the inferred ions (dashed line) are obtained from the measured electron densities applying Eq. (1).

reached an apogee of $377 \mathrm{~km}$. Among the scientific instruments, most of which required a high altitude, it carried a wave propagation experiment to measure (absolute) electron densities, a positive ion probe, a simple detector for charged dust, and a photometer to measure atomic oxygen (Enell et al., 2011). Due to the high apogee, the time spent in the mesosphere was short and therefore the altitude resolution rather poor. Figure 3 shows the results of these four instruments. In addition to the measurements (electrons, ions, $\mathrm{O}$, and dust), the dashed line indicates the ion density inferred from the electron density applying Eq. (1). Below $85 \mathrm{~km}$ a value for $\beta / \alpha_{\mathrm{i}}$ of $5 \times 10^{-32} \mathrm{~m}^{3}$ leads to the best agreement between measured and inferred ions. This value is considerably smaller than the one expected using the values obtained more than 40 years ago under laboratory conditions $\left(2.5 \times 10^{-31} \mathrm{~m}^{3}\right.$, i.e. Phelps, 1969 , for $\beta$, and Peterson et al., 1971, for $\alpha_{\mathrm{i}}$ ). However, from the analysis of $\beta / \alpha_{\mathrm{i}}$ from 28 sounding rockets a mean value of only $8.5 \times 10^{-32} \mathrm{~m}^{3}$ emerged (Friedrich et al., 2011), i.e. reasonably close to the present value. In the height region 85 to $88 \mathrm{~km}$ the inferred ion density is a little less than the measured one. This discrepancy can either be remedied by varying the $\beta / \alpha_{\mathrm{i}}$ with height, or be explained by a more effective electron loss process than provided by gas phase chemistry alone. The negatively charged dust actually measured can provide this additional electron scavenger. Also, according to conventional ion-chemical models (cf. Fig. 1), negative ions can not exist in the presence of the appreciable number density of atomic oxygen as was actually measured in this flight. We can therefore conclude that what at lower altitudes one would explain as negative ions, at these relatively high altitudes where atomic oxygen prevails, the negative charges (other than electrons) are most likely negatively charged dust particles.

In December 2010 the final three of the series of nine ECOMA payloads were launched from Andøya. The primary aim of these rocket soundings was to investigate the distribution, properties and abundance of meteoric dust particles, which - according to theoretical models - are expected to maximise in the mesosphere (e.g. Hunten et al., 1980; Bardeen et al., 2008; or Megner et al., 2008). The main instrument on these payloads is the actual ECOMA detector (= Existence and Charge State of Meteoric Dust Grains in the Middle Atmosphere). In addition, an intermittent UV source ionises neutral particles to make them too detectable (Rapp and Strelnikova, 2009; Fig. 4). The purpose of the final campaign in December 2010 was to investigate whether the well predictable Geminid meteor shower had a noticeable direct influence on the dust observed in the mesosphere.

The ECOMA instrument is designed for a typical velocity of about $1 \mathrm{~km} \mathrm{~s}^{-1}$ into the detector for naturally charges particles to be detectable. Direct Simulation Monte Carlo (DMSC) calculations with the geometry used here (Hedin et al., 2007) have shown that the ram pressure inside the Faraday cup is such that it effectively discriminates lighter masses. Above $80 \mathrm{~km}$ the minimum detectable radius of such particles (assuming a specific mass of 2 to $3 \mathrm{~g} \mathrm{~cm}^{-3}$ ) is about 4 to $5 \mathrm{~nm}$ (Rapp and Strelnikova, 2009). At higher altitudes (less atmospheric density), the detection threshold of mass or radius of the particles is smaller. Hence the upper limit of the height where such an instrument detects particles is quantitatively more meaningful than the lower edge of the occurence of detected particles; that lower altitude limit is more instrumental than geophysical. 

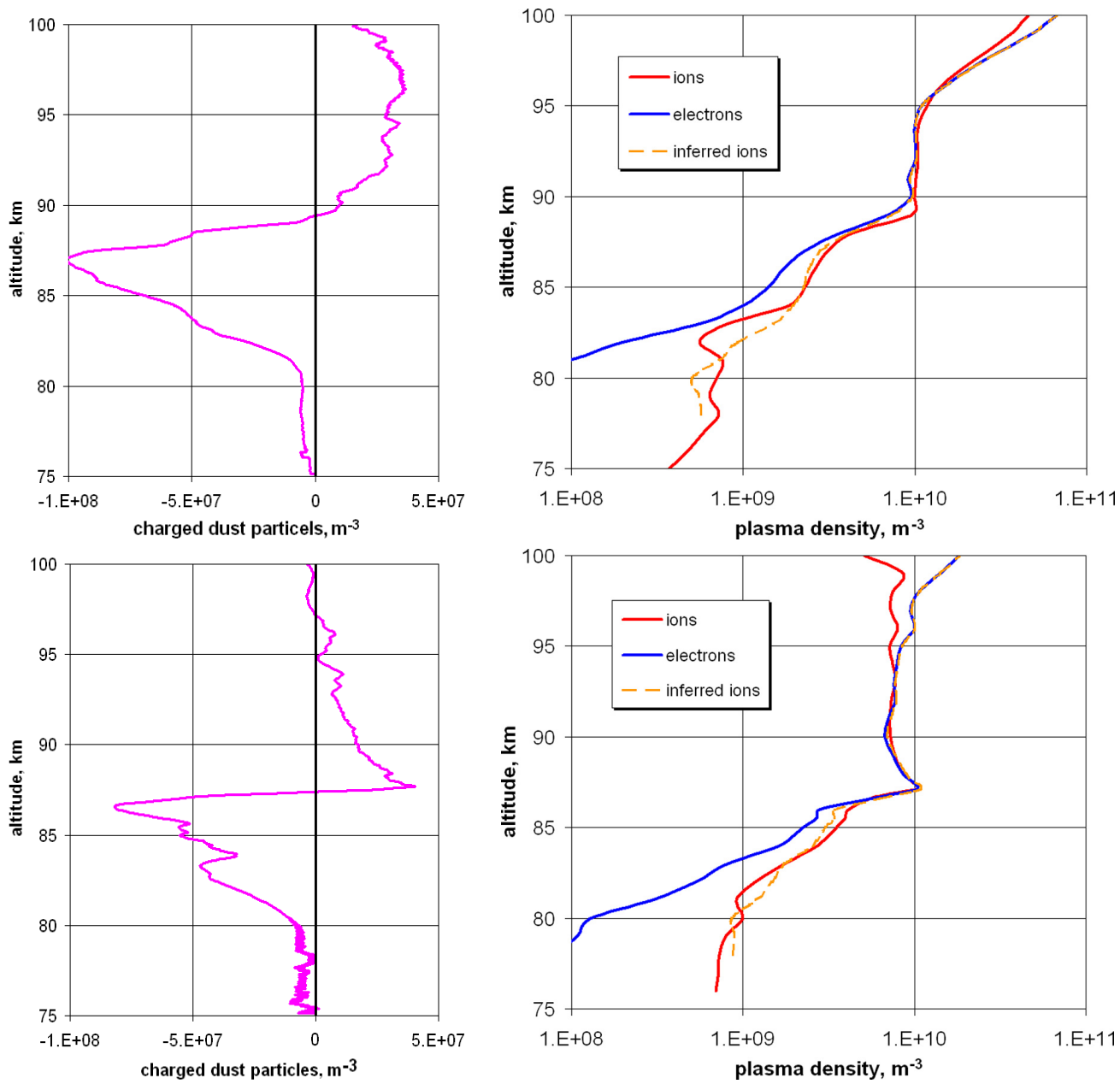

Fig. 6. As in Fig. 5, but for flight 8 (top) and 9 (bottom). Note again that the positive currents seen above 89 and 87 km (ECOMA- 8 and -9 , respectively) are indications of incomplete shielding from positive ions and not signatures of positively charged particles (Rapp et al., 2012).
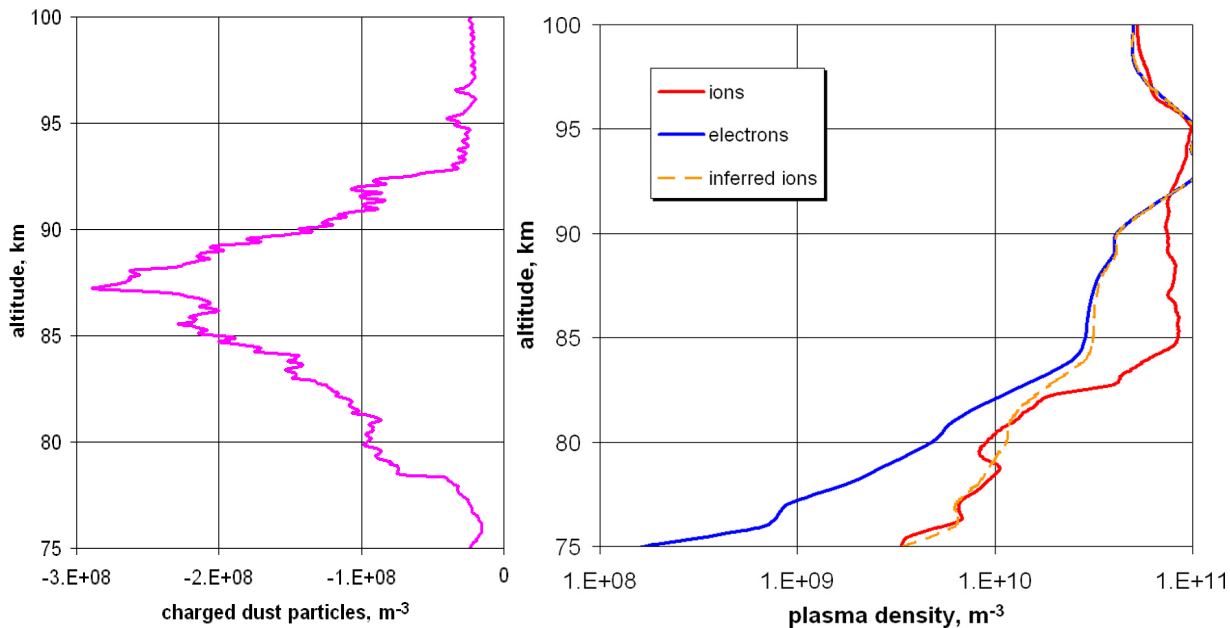

Fig. 7. As in Fig. 4, but flight 41.094 (upleg data). The charged dust particles are of the mass range 500 to $2000 \mathrm{amu}$.

Figure 5 shows the number densities of the detected naturally charged particles of ECOMA-7 together with the elec- tron and ion densities of that flight. For the measurement of 
the ion density not only the dedicated spherical gridded probe (positive ion probe, PIP) could be used (Fig. 4), but also the current of the shielding grid that protects the entrance of the ECOMA detector from ionospheric plasma. The current collected by this grid, biased by $-3 \mathrm{~V}$, was monitored by a low resolution housekeeping channel. Treating this configuration as a plane Langmuir probe yields ion densities typically too large by a factor of 100 , but normalising the nominal profile to the electron density profile at the prominent peak at $97 \mathrm{~km}$ leads to reasonable ion densities (cf. the accompanying paper by Friedrich et al.). Interestingly in the height region 86 to $95 \mathrm{~km}$ the ion density obtained from the exposed shielding grid is consistently larger than what PIP measures. This can plausibly be explained by mass discrimination of PIP due to the relatively low bias on the inner collector $(-2.5 \mathrm{~V})$, whereas no significant mass discrimination can be expected by using the exposed grid as a Langmuir probe. This explanation suggests that the negative population must have contained a significant fraction of heavy particles. There is a clear anticorrelation between negative charged particles and electrons at $91.7 \mathrm{~km}$, but also - although less pronounced - at $93.8 \mathrm{~km}$ strengthening the argument that electrons are lost by attachment to dust particles. To obtain the inferred ions here a value of $\beta / \alpha_{i}$ of $3.0 \times 10^{-32} \mathrm{~m}^{3}$ is used, again much lower than the lab values suggest, but again fairly close to the mean ionospheric experimental value. Below $89 \mathrm{~km}$ this line reasonably tracks the measured ion density, but between 89 and $94 \mathrm{~km}$, the density of inferred ions approach that of electrons, whereas the ion densities measured by PIP are somewhat larger, and considerably larger when derived from the grid current. We again attribute this discrepancy to an electron scavenging process more effective than predicted by Eq. (1), arguably due to attachment onto the meteoric aerosols observed by the ECOMA detector.

The corresponding comparisons with the data of the flights ECOMA-8 and -9 do not show any discernible correlation in fine structure details, but the altitude of the disappearance of negative charged particles strikingly agrees with the altitudes where the densities of electrons and ions converge (Fig. 6). Also, the ion densities derived from the ECOMA grid on average do not deviate from those obtained by PIP. The ion densities of flight ECOMA-8 are of poorer quality, which may explain why there is no discernible difference between inferred and measured ions (cf. Friedrich et al., 2012). The maximum in the charged particles of ECOMA9 at $86 \mathrm{~km}$ does seem to be reflected in the plasma density data, again strengthening the argument that heavy particles scavenge free electrons. The fact that details of the charged particle densities are more clearly reflected in the electron densities of the order of $10^{7}$ to $10^{8} \mathrm{~m}^{-3}$, explains plausibly that corresponding fine structures are better visible on a background electron density profile with densities that are of the same order of magnitude than in the case where the electron density is much larger than the charged particles density.
The most recent and most convincing case is provided by the data of the rocket flight CHAMPS (41.094), also from Andøya. The rocket axis was actively kept within $1.4^{\circ}$ to the velocity vector, both on up- and downleg and guaranteed high quality measurements throughout the whole flight. In contrast to the payloads discussed so far, here the particles were not detected by a Faraday cup, but by a mass spectrometer with four mass ranges for each polarity (an early version of this mass spectrometer is described by Knappmiller et al., 2008). Figure 7 shows the negatively charged masses in the range 500 to $2000 \mathrm{amu}$, the range which best correlates with the difference between measured and inferred ions (upleg data).

Table 1 lists the pertinent details of the present flights all of which occurred under full darkness (solar zenith angles $\chi>98^{\circ}$ ). Under "comments" in Table 1, the reasons are listed why these two earlier flights are not fully considered in the present context; why we concentrate on the three ECOMA flights is primarily that they carried identical instruments, had (almost) identical trajectories, and thus assured comparable aerodynamic behaviour of the particle detectors.

\section{Conclusions}

The charge balance observed by recent nighttime, high latitude rocket flights shows negative charges - other than electrons - which are significantly different in the five cases. The charged large particles measured by the same rockets typically disappear at about the same maximum altitudes as the negative charges derived from the plasma measurements. This strongly suggests that the depletion of free electrons is caused by the large particles in addition to the usual gas phase chemistry by which the existence of negative ions in the lower ionosphere is conventionally explained.

A similar correlation at the bottom of the particle layer and the electron depletion is not expedient because flow conditions in the denser air are such that the detection threshold for the particles is shifted to larger particle sizes/larger masses of which much smaller concentrations are expected. A further indication for electron scavenging by heavy particles is given by the anti-correlation of density structure details between negatively charged particles and electrons.

Finally, the presence of appreciable atomic oxygen, as actually measured by HotPay-2, destroys negative ions, but does not affect electrons attached to dust particles; this is an important argument for the hypothesis that dust acts as an electron scavenger.

Acknowledgements. The Austrian participation in the ECOMA and CHAMPS series of rocket flights was made possible by grants 18560 and 23100 of the Austrian Research Fund (FWF). The German part of the ECOMA project was funded by the German Space Agency (DLR) under grants 50 OE 0301 and 50 OE 0801 . The flight 41.094 (CHAMPS) was supported by 
NASA's programme Low Cost Access to Space.

Topical Editor C. Jacobi thanks E. Thrane and one anonymous referee for their help in evaluating this paper.

\section{References}

Bardeen, C. G., Toon, O. B., Jensen, E. J., Marsh, D. R., and Harvey, V. L.: Numerical Simulations of the Three-Dimensional Distribution of Meteoric Dust in the Mesosphere and Upper Stratosphere, J. Geophys. Res., 113, D17202, doi:10.1029/2007JD009515, 2008.

Enell, C.-F., Hedin, J., Stegman, J., Witt, G., Friedrich, M., Singer, W., Baumgarten, G., Kaifler, B., Hoppe, U.-P., Gustavsson, B., Brändström, U., and Khaplanov, M.: The Hotel Payload 2 Campaign: Overview of NO, O and Electron Density Measurements in the Upper Mesosphere and Lower Thermosphere, J. Atmos. Solar Terr. Phys., 73, 2228-2236, 2011.

Friedrich, M., Gumbel, J., and Pilgram, R.: Atomic Oxygen in the Mesosphere and its Relevance for the Ionosphere, ESA SP-437, pp. 287-290, 1999.

Friedrich, M., Rapp, M., Plane, J. M. C., and Torkar, K. M.: Bite-Outs and Other Depletions of Mesospheric Electrons, J. Atmos. Solar Terr. Phys., 73, 2201-2211, doi:10.1016/j.jastp.2010.10.018, 2011.

Friedrich, M., Torkar, K. M., Hoppe, U.-P., Bekkeng, T.-A., and Rapp, M.: Multi-Instrument Comparisons of $D$-Region Plasma Measurements, Ann. Geophys., in review, 2012.

Gumbel, J.: Rocket Borne Optical Measurements of Minor Constituents in the Middle Atmosphere, Ph.D. Thesis, Stockholm University, 1997.

Hedin, J., Gumbel, J., and Rapp, M.: On the efficiency of rocketborne particle detection in the mesosphere, Atmos. Chem. Phys., 7, 3701-3711, doi:10.5194/acp-7-3701-2007, 2007.

Hunten, D. M., Turco, R. P., and Toon, O. B.: Smoke and Dust Particles of Meteoric Origin in the Mesosphere and Stratosphere, J. Atmos. Sci., 37, 1342-1357, 1980.

Kassa, M., Rapp, M., Hartquist, T. W., and Havnes, O.: Secondary charging effects due to icy dust particle impacts on rocket payloads, Ann. Geophys., 30, 433-439, doi:10.5194/angeo-30-4332012, 2012.
Knappmiller, S., Sternovsky, Z., Robertson, S., and Friedrich, M.: A Rocket Borne Mass Analyzer for Charged Aerosol Particles in the Mesosphere, Rev. Sci. Instrum., 79, 104502, doi:10.1063/1.2999580, 2008.

Megner, L., Gumbel, J., Rapp, M., and Siskind, D. E.: Reduced Meteoric Smoke Particle Density at the Summer Pole - Implications for Mesospheric Ice Particle Nucleation, Adv. Space Res., 41, 41-49, 2008.

Peterson, J. R., Abert, W. H., Moseley, J. T., and Sheridan, J. H.: Ion-Ion Mutual Neutralization Cross Section Measured by Superimposed Beam Technique, III O $\mathrm{O}_{2}^{+}+\mathrm{O}_{2}^{-}, \mathrm{O}_{2}^{+}+\mathrm{NO}_{2}^{-}$, and $\mathrm{NO}^{+}+\mathrm{NO}_{2}^{-}$, Phys. Rev., 3A, 1651-1657, 1971.

Phelps, A. V.: Laboratory Studies of Electron Attachment and Detachment Processes of Aeronomic Interest, Can. J. Chem., 47, 1783-1793, 1969.

Rapp, M.: Charging of mesospheric aerosol particles: the role of photodetachment and photoionization from meteoric smoke and ice particles, Ann. Geophys., 27, 2417-2422, doi:10.5194/angeo-27-2417-2009, 2009.

Rapp, M. and Strelnikova, I.: Measurement of Meteor Smoke Particles During the ECOMA-2006 Campaign: 1. Particle Detection by Active Photoionization, J. Atmos. Sol. Terr. Phys., 71, 477485, doi:10.1016/j.jastp.2008.06.002, 2009.

Rapp, M., Hedin, J., Strelnikova, I., Friedrich, M., Gumbel, J., and Lübken, F.-J.: Observations of Positively Charged Nanoparticles in the Nighttime Polar Mesosphere, Geophys. Res. Lett., 32, L23821, doi:10.1029/2005GL024676, 2005.

Rapp, M., Strelnikova, I., Strelnikov, B., Friedrich, M., Gumbel, J., Hoppe, U.-P., Blix, T., Havnes, O., Bracikowski, P., Lynch, K., and Knappmiller, S.: Microphysical Properties of Mesospheric Aerosols: An Overview of in situ Results from the ECOMA-Projects, in: Aeronomy of the Earth's Atmosphere and Ionosphere, pp. 67-74, Springer Science+Business Media B.V., edited by: Abdu, M. A., Pancheva, D., and Bhattacharyya, A., IAGA Special Sopron Book Series, doi:10.1007/978-94-0070326-1_4, 2011 